\title{
Coberturas vegetais, doses de nitrogênio e inoculação de sementes com Azospirillum brasilense em arroz de terras altas no sistema plantio direto
}

\author{
Douglas de Castilho Gitti (*); Orivaldo Arf; José Roberto Portugal; Daiene Camila Dias Chaves Corsini; \\ Ricardo Antônio Ferreira Rodrigues; Flávio Hiroshi Kaneko \\ Universidade Estadual Paulista, Faculdade de Engenharia de Ilha Solteira (FEIS-UNESP), Departamento de Fitotecnia, Tecnologia de \\ Alimentos e Sócio-Economia, 15385-000 Ilha Solteira (SP), Brasil. \\ $\left(^{*}\right)$ Autor correspondente: gittidouglas@hotmail.com
}

Recebido: 18/mar./2012; Aceito: 22/out./2012

\begin{abstract}
Resumo
O arroz é importante fonte de energia e proteínas para a população mundial, principalmente na Ásia e Oceania. No Brasil, juntamente com o feijão, constitui a base da alimentação. Tecnologias sustentáveis que reduzam custos da produção e aumentem a produtividade do arroz podem garantir seu suprimento em períodos de alta demanda. O objetivo deste trabaIho foi avaliar diferentes coberturas vegetais antecessoras (milheto [Pennisetum americanum], crotalária [Crotalaria juncea], guandu [Cajanus cajan], braquiária [Brachiaria ruziziensis], milheto + crotalária e milheto + guandu), doses de nitrogênio ( $\mathrm{N}$ ) em cobertura $\left(0,40,80\right.$ e $\left.120 \mathrm{~kg} \mathrm{ha}^{-1}\right)$ e o efeito da inoculação de sementes com Azospirillum brasilense no arroz de terras altas em sistema plantio direto no desenvolvimento e na produtividade. Utilizou-se o delineamento experimental em blocos casualizados em esquema fatorial $6 \times 4 \times 2$ com quatro repetições. 0 estudo foi desenvolvido em um Latossolo Vermelho, em Selvíria, Estado do Mato Grosso do Sul, Brasil, em 2011/2012. O cultivo do guandu antecedendo o arroz proporcionou maior produtividade do arroz somente em comparação a B. ruziziensi. A produtividade do arroz em função das doses de $\mathrm{N}$ em cobertura se ajustou a uma função quadrática. Não houve influência da inoculação de sementes com A. brasilense sobre a produtividade do arroz, porém houve interação entre a inoculação e as coberturas vegetais sobre o teor de $\mathrm{N}$ foliar, número de panículas por $\mathrm{m}^{2}$, matéria seca de plantas de arroz e a massa de cem grãos.
\end{abstract}

Palavras-chave: Crotalaria juncea, Cajanus cajan, Oryza sativa, Pennisetum americanum, bactéria diazotrófica.

\section{Cover crops, nitrogen rates and seeds inoculation with Azospirillum brasilense in upland rice under no-tillage}

\footnotetext{
Abstract

Rice is an important source of energy and protein for the world population, mainly in Asia and Oceania. In Brazil, together with common beans, it is the population's basic food. Sustainable technologies that reduce rice production costs and increase productivity can warrant its supply on period of high demand. The objective of this study was to evaluate different preceding cover crops (millet [Pennisetum americanum], sunn hemp [Crotalaria juncea], pigeon pea [Cajanus cajan], Brachiaria ruziziensis, millet + sunn hemp and millet + pigeon pea), rates of nitrogen (N) fertilization at sidedressing (0,40, 80 and $\left.120 \mathrm{~kg} \mathrm{ha}^{-1}\right)$ and the effects of seed inoculation with Azospirillum brasilense in upland rice under no-tillage system on crop growth and yield. The experimental design was in complete randomized blocks, in a factorial scheme 6x4x2 with four replications. The experiment was set up on a Red Oxisol in Selvíria, State of Mato Grosso do Sul, Brazil, in 2011/2012. Pigeon pea preceding rice cropping provided higher rice yield only in comparison with B. ruziziensis. The rice yield as function of rates of $\mathrm{N}$ at sidedressing fit to a quadratic function. There was no influence of seeds inoculation with A. brasilense on rice yield, however, there was interaction between the inoculation and cover crops on the leaf of $\mathrm{N}$ content, number of panicles per $\mathrm{m}^{2}$, dry rice plants and weight of 100 grains.
}

Key words: Crotalaria juncea, Cajanus cajan, Oryza sativa, Pennisetum americanum, diazotrophic bacteria. 


\section{INTRODUÇÃO}

A produção brasileira de arroz concentra-se no Sul do país com $75 \%$ da produçáo nacional, sendo o sistema de cultivo irrigado por inundaçáo predominante na regiáo. $\mathrm{O}$ desenvolvimento de tecnologias para o aumento da produtividade do arroz no sistema terras altas é importante, uma vez que podem ser utilizadas por pequenos e grandes produtores que não utilizam o sistema irrigado na maioria dos Estados brasileiros.

O arroz foi utilizado como cultura pioneira em área de fronteiras agrícolas e, atualmente, com a redução da abertura de novas áreas agrícolas, sua utilização deverá compor sistema de cultivos com rotação de culturas, principalmente em áreas com o SPD. A cobertura do solo pela palha é fundamental para a sustentabilidade do SPD, pois proporciona benefícios para propriedades físicas, químicas e biológicas do solo. Para o cultivo do arroz em SPD, as plantas de cobertura sáo de grande interesse, pois entre os nutrientes liberados pela palha, o $\mathrm{N}$ é disponibilizado na forma de amônio (Teixeira et al., 2009), importante para o desenvolvimento inicial do arroz.

A disponibilidade de nutrientes pelos resíduos vegetais esta relacionado à relação $\mathrm{C} / \mathrm{N}$ da palha. As leguminosas utilizadas para cobertura vegetal proporcionam maior aporte de $\mathrm{N}$ no solo (Perin et al., 2004; Teodoro et al., 2011) e podem aumentar a produtividade do arroz de terras altas em sucessão no SPD (CAzetTa et al., 2008). As gramíneas aumentam a permanência da palha sobre a superfície do solo, pela maior relação $\mathrm{C} / \mathrm{N}$, e assim, menor velocidade de decomposição (Torres et al., 2008).

A fixação biológica do $\mathrm{N}$ pelas bactérias do gênero Azospirillum em associaçáo com gramíneas (DöBEREINER et al., 1976) podem contribuir com o fornecimento de parte das necessidades das plantas por este nutriente. Esse grupo de bactérias também sintetizam hormônios, como a auxina, que estimula o crescimento da parte aérea e do sistema radicular de varias gramíneas, entre elas o arroz (RADWAN et al., 2004).

Tendo em vista o exposto, o objetivo do trabalho foi avaliar diferentes coberturas vegetais, doses de $\mathrm{N}$ na presença e ausência da inoculação de sementes com $A$. brasilense no arroz de terras altas cultivado em SPD no desenvolvimento e na produtividade da cultura.

\section{MATERIAL E MÉTODOS}

O experimento foi desenvolvido em 2011/2012, no município de Selvíria (MS), a $340 \mathrm{~m}$ de altitude. O clima da região, segundo classificação de Koppen, é do tipo Aw, com precipitaçáo pluvial média anual de $1.330 \mathrm{~mm}$, temperatura média anual de $25{ }^{\circ} \mathrm{C}$ e umidade relativa do ar média anual de $66 \%$.
O solo foi classificado como Latossolo Vermelho distrófico álico e de textura argilosa (EMBRAPA, 2006), cujas características químicas da camada de 0 a $0,20 \mathrm{~m}$ foram: $\mathrm{P}$ (resina) $=34 \mathrm{mg} \mathrm{dm}^{-3} ; \mathrm{MO}=22 \mathrm{~g} \mathrm{dm}^{-3}$; $\mathrm{pH}\left(\mathrm{CaCl}_{2}\right)=5,1 ; \mathrm{K}=2,8 \mathrm{mmol}_{\mathrm{c}} \mathrm{dm}^{-3} ; \mathrm{Ca}=17 \mathrm{mmol} \mathrm{dm}_{\mathrm{c}}$; $\mathrm{Mg}=11 \mathrm{mmol} \mathrm{dm}_{\mathrm{c}}^{-3} ; \mathrm{H}+\mathrm{Al}=31 \mathrm{mmol} \mathrm{dm}^{-3} ; \mathrm{Al}=1 \mathrm{mmol} \mathrm{dm}^{-3}$; CTC $=61,8 \mathrm{mmol}_{c} \mathrm{dm}^{-3} \mathrm{eV}(\%)=50$. A área está sendo cultivada em sistema SPD desde o ano agrícola 1997/1998. Nos anos agrícolas 2009/2010, 2010/2011 e 2011/2012 foram utilizadas como coberturas vegetais o milheto, a crotalária, área em pousio, milheto + crotalária e milheto + guandu na primavera, mantendo-as sempre nas mesmas áreas, com alteração da área em pousio para $B$. ruzizienses, em 2011/2012. No verão e inverno, cultivaram-se, respectivamente, arroz e trigo, nos três anos agrícolas (2009/2010, 2010/2011 e 2011/2012).

O delineamento experimental foi o de blocos casualizados em esquema fatorial $6 \times 4 \times 2$ com quatro repetiçóes, sendo 48 tratamentos constituídos pela combinação de seis coberturas vegetais: milheto (Pennisetum americanum), crotalária (Crotalaria juncea), guandu (Cajanus cajan), milheto + crotalária, milheto + guandu e braquiária (Brachiaria ruziziensis); quatro doses de $\mathrm{N}$ em cobertura $\left(0,40,80\right.$ e $120 \mathrm{~kg} \mathrm{ha}^{-1}$ de $\left.\mathrm{N}\right)$ na presença e ausência de inoculação de sementes com $A$. brasilense. As parcelas foram constituídas por cinco linhas com $6 \mathrm{~m}$ de comprimento e espaçadas $0,35 \mathrm{~m}$ entre si. Foram utilizadas para coleta dos dados três linhas centrais, de cada parcela, desprezando-se $0,50 \mathrm{~m}$ nas extremidades.

A semeadura das coberturas vegetais foi realizada em $31 / 8 / 2011$. Utilizou-se semeadora tratorizada com espaçamento de $0,45 \mathrm{~m}$ para demarcação das linhas e a semeadura das coberturas vegetais foi realizada manualmente utilizando-se matracas, sem adubação. As densidades de semeadura foram de $15,40,20$ e $8 \mathrm{~kg} \mathrm{ha}^{-1}$ de sementes para milheto, crotalária, guandu e braquiária respectivamente. Para os consórcios, foram mantidas as densidades de semeadura e intercaladas as linhas com as coberturas vegetais consorciadas. O fornecimento de água, quando necessário, foi realizado por um sistema fixo de irrigação por aspersão com precipitação de $3,3 \mathrm{~mm}^{\text {hora }}{ }^{-1}$. A lâmina e o turno de rega foram de $10 \mathrm{~mm}$ a cada 3 dias. Em 27/10/2011, aos 57 dias após a semeadura das coberturas vegetais, foi realizada aplicação dos herbicidas $2,4 \mathrm{D}$ (1209 $\mathrm{g} \mathrm{ha}^{-1}$ do i.a.) e glifosato (1440 $\mathrm{g} \mathrm{ha}^{-1}$ do i.a.) para dessecação das plantas existentes na área experimental $\mathrm{e}$ em 1.\%11/2011, a área foi manejada com desintegrador mecânico Triton ${ }^{\circ}$, para facilitar a implantação da cultura e demarcação das parcelas experimentais.

A semeadura do arroz foi realizada mecanicamente em 3/11/2011, utilizando-se cv. ANa 5011 de de grãos tipo longo-fino, porte médio, moderadamente suscetível ao acamamento e ciclo de aproximadamente 90 dias; após a semeadura, foi realizada a compactação das linhas de semeadura utilizando trator Yanmar 1145-4. 
A densidade de semeadura utilizada foi de $80 \mathrm{~kg} \mathrm{ha}^{-1}$. $\mathrm{O}$ tratamento de sementes foi realizado com o inseticida fipronil (50 g por $100 \mathrm{~kg}$ de sementes do i.a.), visando ao controle de pragas do solo.

Após o tratamento de sementes com inseticida e, pouco antes da semeadura do arroz, foi realizada a inoculação de sementes com $A$. brasilense. A inoculação foi realizada à sombra, com as estirpes Ab-V5 e Ab-V6. No inoculante utilizado havia $2 \times 10^{8}$ células viáveis por grama do produto comercial, utilizando-se a dose de $200 \mathrm{~g}$ de inoculante para $25 \mathrm{~kg}$ de sementes. A adubação básica de semeadura foi de $250 \mathrm{~kg} \mathrm{ha}^{-1} \mathrm{da}$ fórmula 04-30-10.

A emergência da cultura ocorreu em 8/11/2011, aos cinco dias após a semeadura. As doses de $\mathrm{N}$ em coberturas foram realizadas aos 22 dias após a emergência (DAE), utilizando como fonte de $\mathrm{N}$ a uréia. A aplicação do fertilizante nitrogenado foi realizada de forma manual em cobertura superficial a lanço (sem incorporação), seguida de irrigação por aspersão (lâmina de aproximadamente $10 \mathrm{~mm}$ ), para minimizar as perdas de $\mathrm{N}$ por volatilização da amônia.

O controle de plantas daninhas foi realizado com o herbicida pré-emergente pendimenthalin $\left(1120 \mathrm{~g} \mathrm{ha}^{-1} \mathrm{do}\right.$ i.a.) logo após a semeadura do arroz, visando ao controle principalmente de folhas estreitas. Em pós-emergência (11 DAE), utilizou-se o herbicida metsulfuron-metílico (1,8 g ha $^{-1}$ do i.a.) para controle das plantas daninhas de folhas largas. Quanto ao controle de pragas e doenças, não houve necessidade da aplicação de produtos fitossanitários para esta finalidade.

A colheita foi realizada manualmente em 11/2/2012, aos 93 DAE. A trilha foi realizada mecanicamente e os grãos foram submetidos à secagem à sombra.

Foram realizadas as seguintes avaliaçóes: a) Matéria seca das coberturas vegetais (MSCV): após o manejo das coberturas vegetais com Triton ${ }^{\oplus}$, coletou-se a matéria seca das coberturas vegetais com um quadrado de $0,5 \mathrm{~m}$ de lado e área de $0,25 \mathrm{~m}^{2}$, em dois pontos por parcela e levadas para secagem em estufa de ventilação forçada à temperatura de $65^{\circ} \mathrm{C}$ até ponto de equilíbrio constante, e extrapolando os resultados para $\mathrm{kg} \mathrm{ha}^{-1}$; b) Teores de N, P e K total acumulado na MSCV: foram determinados os teores de N, P e K $\left(\mathrm{g} \mathrm{kg}^{-1}\right)$ das coberturas vegetais, conforme método proposto por Malavolta et al. (1997). Pelo produto do teor de nutrientes e os valores extrapolados da MSCV ( $\mathrm{kg} \mathrm{ha}^{-1}$ ), obteve-se o N, P e K total acumulado pelas coberturas vegetais; c) Matéria seca da parte aérea do arroz (MSPA): no florescimento, foram coletados por unidade experimental dois pontos de $0,20 \mathrm{~m}$ de linha da parte aérea das plantas de duas linhas centrais. A matéria seca foi obtida após secagem das plantas em estufa a $65^{\circ} \mathrm{C}$ com circulação de ar até massa constante e, posteriormente, convertida em $\mathrm{kg} \mathrm{ha}^{-1}$; d) teor de $\mathrm{N}$ foliar: no florescimento, foram coletados os limbos foliares de 30 "folhas- bandeira" por parcela e, após secagem, foram moídas em moinho tipo Wiley, e submetidas à digestão sulfúrica, conforme método descrito em MaLAVOLTA et al. (1997); e) Altura de plantas: distância média compreendida, desde a superfície do solo até a extremidade superior da panícula mais alta, determinada na maturaçáo, em 10 plantas ao acaso por parcela; f) Acamamento de plantas: observaçóes visuais na maturação, utilizando-se a seguinte escala de notas: 0 - sem acamamento; 1 - até $5 \%$ de plantas acamadas; $2-5 \%$ a $25 \%, 3-25 \%$ a $50 \%$; $4-50 \%$ a $75 \%$ e $5-75 \%$ a $100 \%$ de plantas acamadas; g) Número de colmos e panículas: contagem do número de colmos e panículas em $1 \mathrm{~m}$ de fileira de plantas, expressando-se os valores por $\mathrm{m}^{2} ; \mathrm{h}$ ) Número de espiguetas granadas e chochas por panícula: após separação por meio de fluxo de ar foi realizada a contagem do número de espiguetas granadas e chochas de 15 panículas, e convertidos os resultado de espiguetas chochas em porcentagem; i) Massa de cem grãos: pesagem de duas amostras de cem grãos de cada parcela, corrigindo-se para 13\% de umidade (base úmida); j) Produtividade: pesagem dos grãos em casca, provenientes da área útil da parcela, corrigindo-se para $13 \%$ de umidade e extrapolando o valor em $\mathrm{kg} \mathrm{ha}^{-1}$.

Os resultados foram submetidos ao teste $\mathrm{F}$ da análise de variância. Constatado resultado significativo pelo teste $\mathrm{F}(\mathrm{p}<0,01$ e $\mathrm{p}<0,05)$, foi realizada a comparaçáo de médias pelo teste de Tukey $(\mathrm{p}<0,05)$ para as coberturas vegetais e inoculação de sementes, e regressão polinomial para as doses de nitrogênio.

\section{RESULTADOS E DISCUSSÃO}

O cultivo das coberturas vegetais anterior ao arroz, visando à produção de palha e à rotaçáo de culturas para sustentabilidade do SPD, proporcionou o maior valor de MSCV (Tabela 1) com o consórcio de milheto + crotalária $\left(5779 \mathrm{~kg} \mathrm{ha}^{-1}\right)$, em relaçáo ao cultivo de guandu, braquiária e o consórcio milheto + guandu (2504, 2832 e $3837 \mathrm{~kg} \mathrm{ha}^{-1}$, respectivamente). Nas demais coberturas vegetais: milheto e crotalária (4784 e $5286 \mathrm{~kg} \mathrm{ha}^{-1}$ respectivamente), os valores foram semelhantes aos consórcios milheto + crotalária e milheto + guandu. CAZETTA et al. (2008) obtiveram valores semelhantes para o guandu $\left(2697 \mathrm{~kg} \mathrm{ha}^{-1}\right)$ e superiores para a crotalária $\left(6023 \mathrm{~kg} \mathrm{ha}^{-1}\right)$ e milheto $\left(7282 \mathrm{~kg} \mathrm{ha}^{-1}\right)$, em cortes aos 60 dias após a semeadura, nas mesmas condições de solo e épocas de semeadura das coberturas vegetais.

Os teores de N, P e K total acumulado na MSCV tiveram diferenças significativas (Tabela 1). O milheto + crotalária obteve os maiores valores de $\mathrm{N}, \mathrm{P}$ e $\mathrm{K}$ totais acumulados (74,9; 15,6 e 124,6 respectivamente) em relação à braquiária $(42,7 ; 8,2 ;$ e 70,4$)$ e ao guandu $(44,4 ; 8,4$ e 54,1$)$. Os teores de N, P e K do milheto + crotalária e do milheto + guandu (56,2; 12,2 e 79,7, respectivamente) náo diferiram dos seus cultivos exclusivos de milheto $(56,9 ; 14,0$ e 111,2), crotalária $(75,5 ; 14,7$ e 105,5$)$ e guandu, mostrando semelhança na 
Tabela 1. Valores médios da matéria seca das coberturas vegetais (MSCV), teor de nitrogênio (N), fósforo (P) e potássio (K) total acumulado na massa seca das coberturas vegetais cultivadas anteriormente ao arroz de terras altas no sistema plantio direto. Selvíria (MS), Brasil, 2012

\begin{tabular}{|c|c|c|c|c|}
\hline \multirow{2}{*}{ Tratamento } & MSCV & $\mathbf{N}$ & $\mathbf{P}$ & K \\
\hline & $\left(\mathrm{kg} \mathrm{ha}^{-1}\right)$ & \multicolumn{3}{|c|}{ total acumulado (kg ha-1) } \\
\hline \multicolumn{5}{|l|}{ Cobertura vegetal $(C)$} \\
\hline Milheto & $4784 a b$ & $56,9 a b$ & $14,0 a b$ & $111,2 \mathrm{ab}$ \\
\hline Crotalária & $5286 a b$ & $75,5 \mathrm{a}$ & $14,7 \mathrm{a}$ & $105,5 a b$ \\
\hline Guandu & $2504 c$ & $44,4 \mathrm{~b}$ & 8,4 bc & $54,1 \mathrm{c}$ \\
\hline Braquiária & 2832 c & $42,7 \mathrm{~b}$ & $8,2 \mathrm{c}$ & 70,4 bc \\
\hline Milheto + Crotalária & 5779 a & 74,9 a & $15,6 \mathrm{a}$ & $124,6 \mathrm{a}$ \\
\hline Milheto + Guandu & 3837 bc & $56,2 \mathrm{ab}$ & $12,2 a b c$ & $79,7 \mathrm{abc}$ \\
\hline Teste F & $13,42^{* *}$ & $8,13^{* *}$ & $6,82^{* *}$ & $7,44^{* *}$ \\
\hline DMS (5\%) & 1673 & 22,9 & 5,6 & 45,6 \\
\hline Média geral & 4171 & 58,4 & 12,2 & 90,9 \\
\hline CV (\%) & 17,45 & 17,09 & 20,13 & 21,83 \\
\hline
\end{tabular}

**significativo em nível de $1 \%$ de probabilidade pelo teste F; Médias seguidas por letra iguais nas colunas nấo diferem pelo teste de Tukey em nível de $5 \%$ de probabilidade; DMS: diferença mínima significativa pelo teste de Tukey; CV: coeficiente de variação; MSCV: matéria seca das coberturas vegetais; N: N total acumulado; P: P total acumulado; $\mathrm{K}$ : K total acumulado.

disponibilidade de nutrientes entre os cultivos exclusivos e consorciados. Perin et al. (2004) obtiveram teores de N, P e K na parte aérea da crotalária, milheto + crotalária e milheto, cultivados no verão e manejados aos 68 dias após a semeadura, superiores ao presente trabalho, provavelmente devido à semeadura das coberturas vegetais, realizada no fim do inverno (agosto), quando ocorreu menor produção de fitomassa e menor quantidade de nutrientes.

Analisando o desdobramento das coberturas vegetais dentro da inoculação sobre a MSPA, nota-se que a inoculação de sementes com $A$. brasilense em arroz cultivado em sucessão ao milheto + guandu e ao milheto proporcionou, respectivamente, a maior $\left(8273 \mathrm{~kg} \mathrm{ha}^{-1}\right)$ e menor (6581 kg ha ${ }^{-1}$ ) MSPA (Figura 1a). Quanto ao desdobramento da inoculação dentro das coberturas vegetais, o cultivo do arroz submetido à inoculação $\operatorname{com} A$. brasilense em sucessão ao milheto + guandu resultou na maior MSPA em relação ao tratamento não inoculado. GuimarÃes et al. (2007) também obtiveram aumento da MSPA com inoculação de sementes com $A$. brasilense, em cultivares de arroz para o sistema inundado cultivadas em vasos. Provavelmente, a produção de auxina (Kuss et al., 2007) pode ter estimulado o desenvolvimento do sistema radicular e proporcionado maior absorção de nutrientes refletindo no crescimento da planta e aumento da MSPA. Efeito oposto, ou seja, redução na MSPA, foi observado por SALA et al. (2007), quando sementes de trigo foram submetidas à inoculaçáo com $A$. brasilense e cultivadas na ausência da adubaçáo nitrogenada. As bactérias diazotróficas de não leguminosas não suprem todas as necessidades de $\mathrm{N}$ das plantas (BALDANI e BALDANI, 2005), sendo necessário o fornecimento de parte da necessidade da planta pelos fertilizantes nitrogenados. A maior MSPA do arroz cultivado em sucessão ao milheto + guandu em relação à área de milheto pode ser decorrente do fornecimento de $\mathrm{N}$ pelo guandu.
As doses de $\mathrm{N}$ em cobertura influenciaram a MSPA de maneira linear positiva. A disponibilidade de nutrientes, notadamente de $\mathrm{N}$, em quantidades e épocas adequadas, contribui para estimular o perfilhamento e aumentar o número de panículas por área influenciando positivamente a MSPA (Figura 2).

Analisando o desdobramento das coberturas vegetais dentro da inoculação sobre o teor de $\mathrm{N}$ foliar (Figura 1b), observam-se diferenças no teor de $\mathrm{N}$ foliar do arroz em sucessão às coberturas vegetais na ausência da inoculação de sementes com $A$. brasilense. O cultivo do arroz em sucessão à crotalária obteve o maior valor do teor de $\mathrm{N}$ foliar $\left(29,3 \mathrm{~g} \mathrm{~kg}^{-1}\right)$, em relação à área com milheto, com menor valor $\left(26,6 \mathrm{~g} \mathrm{~kg}^{-1}\right)$. CAZETTA et al. (2008) não obtiveram influência no teor de $\mathrm{N}$ foliar do arroz cultivado em sucessão às coberturas vegetais em épocas semelhantes de cultivo do presente trabalho. As coberturas vegetais estão sendo cultivadas na mesma área há três anos consecutivos, o que pode explicar o maior teor de $\mathrm{N}$ foliar do arroz em sucessão à crotalária, em relação ao milheto. Considerando o desdobramento da inoculaçáo dentro das coberturas vegetais, o cultivo do arroz submetido à inoculaçáo com A. brasilense em sucessão à crotalária proporcionou menor valor $\left(27,3 \mathrm{~g} \mathrm{~kg}^{-1}\right)$ do teor de $\mathrm{N}$ foliar, em relação ao tratamento não inoculado. Entre as coberturas vegetais, no cultivo do arroz em sucessão à crotalária, observou-se o maior teor de $\mathrm{N}$ foliar $\left(29,3 \mathrm{~g} \mathrm{~kg}^{-1}\right)$ do arroz, em relaçáo à área com milheto + guandu. $\mathrm{O} N$ total acumulado na parte aérea (MSCV) da crotalária foi aproximadamente $25 \%$ superior ao milheto + guandu, justificando o maior valor do teor de $\mathrm{N}$ foliar do arroz.

As doses de nitrogênio em coberturas aumentaram linearmente o teor de $\mathrm{N}$ foliar (Figura 2). O aumento das doses de $\mathrm{N}$ elevou a disponibilidade desse nutriente e contribuiu para incrementá-lo linearmente no tecido vegetal. Assim também, Hernandes et al. (2010) obtiveram 

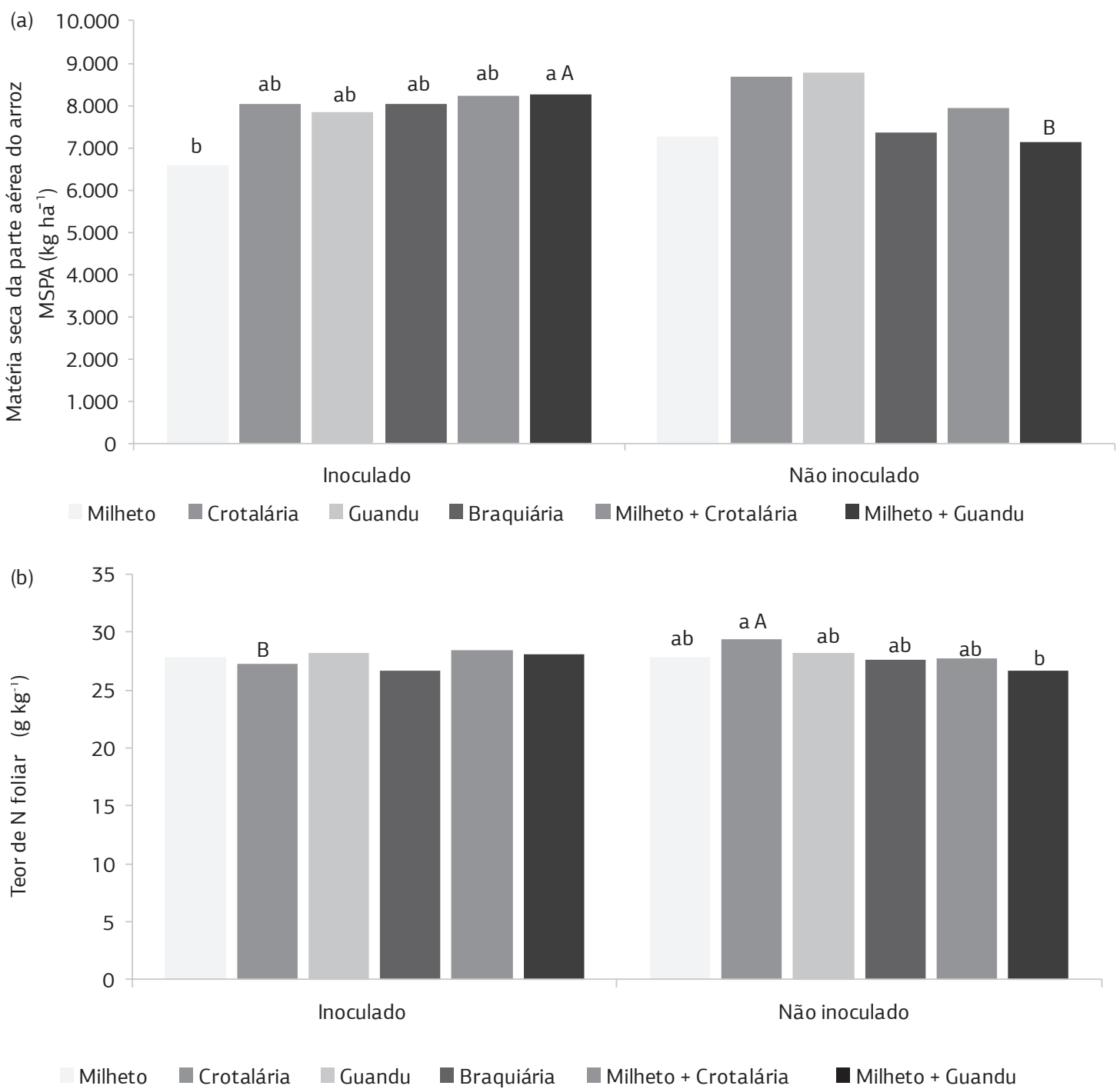

Figura 1. Desdobramento da interação entre coberturas vegetais e inoculação de sementes com $A$. brasilense sobre a MSPA (a) e o teor de N foliar (b). Selvíria (MS), Brasil, 2012. MSPA=coberturas vegetais dentro de inoculação; DMS=1674 (letras minúsculas), inoculaçáo dentro de coberturas vegetais; DMS=1145 (letras maiúsculas). Teor de $\mathrm{N}$ foliar - coberturas vegetais dentro de inoculaçáo; DMS = 2,45 (letras minúsculas), inoculação dentro de coberturas vegetais; $\mathrm{DMS}=1,67$ (letras maiúsculas). Médias seguidas por letra minúsculas e maiúsculas iguais não diferem entre si pelo teste de Tukey a 5\% de probabilidade.

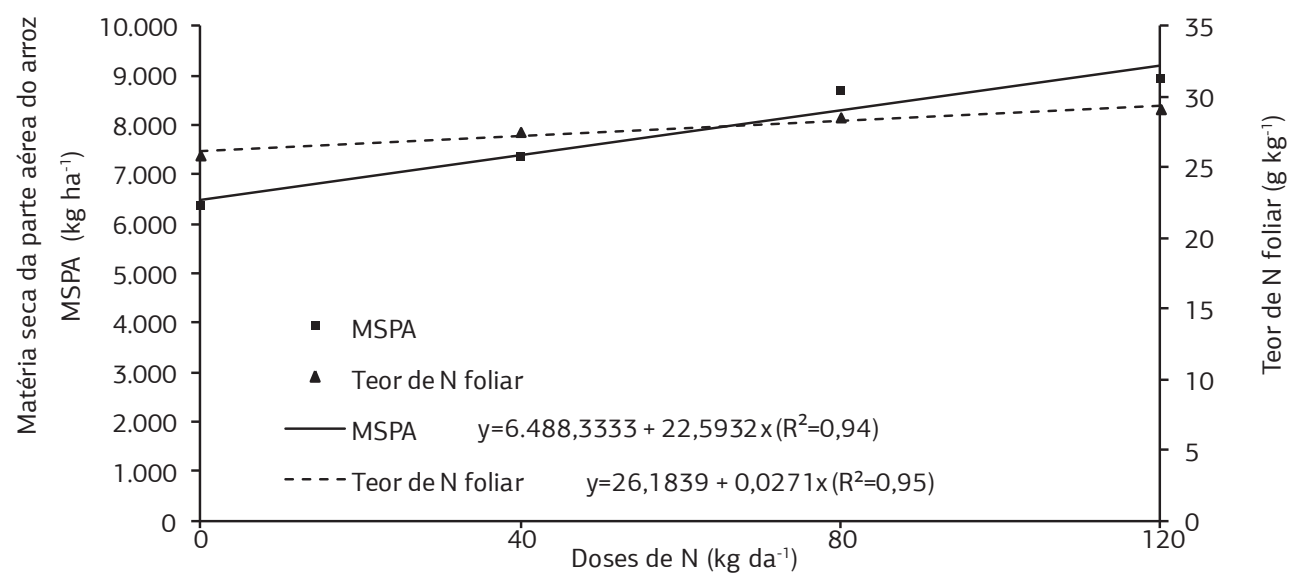

Figura 2. Matéria seca da parte aérea do arroz (MSPA) e teor de $\mathrm{N}$ foliar do arroz de terras altas no sistema plantio direto em função das doses de N em cobertura. Selvíria (MS), Brasil, 2012. 
aumentos lineares no teor de $\mathrm{N}$ foliar com doses de $\mathrm{N}$ em coberturas que chegaram até $200 \mathrm{~kg} \mathrm{ha}^{-1}$.

A altura e o acamamento de plantas do arroz foram influenciados pelas doses de $\mathrm{N}$ em cobertura, sendo os resultados linearmente positivos com aumento das doses (Figura 3). A cultivar avaliada possui baixa resistência ao acamamento de plantas. Seu cultivo em áreas semelhantes ao do presente trabalho, ou seja, com boa fertilidade do solo, fornecimento de nitrogênio em cobertura e utilização de irrigação suplementar pode proporcionar perdas na colheita. A utilização do regulador de crescimento etil-trinexapac contribui para eliminar o acamamento de plantas (NAscimento et al., 2009).

Analisando a influência das coberturas vegetais dentro da inoculação de sementes com $A$. brasilense sobre o NP (Figura 4a), o cultivo do arroz submetido à inoculação e em sucessão ao guandu e ao milheto + guandu tiveram os maiores valores da NP (321 e 314 respectivamente), em relação ao milheto, com menor valor (283). Na ausência da inoculação, a crotalária e o guandu proporcionaram os mais valores do NP (342 e 340 respectivamente), com diferença do arroz cultivado em sucessão ao milheto, com menor valor (280). Quanto à influência da inoculação dentro das coberturas vegetais, o arroz submetido à inoculaçấo e cultivado em sucessão à crotalária, proporcionou redução no NP.

As leguminosas crotalária e guandu contribuem para as qualidades físicas do solo (ANDRADE et al., 2009), como também, a disponibilidade de $\mathrm{N}$, importante nutriente determinante do NP do arroz, como observado no arroz cultivado em sucessão a estas leguminosas, porém na ausência da inoculação de sementes com $A$. brasilense. Foi observado por Rodrigues et al. (2008) redução no desenvolvimento das plantas e raízes pela inoculação de $A$. brasilense em arroz inundado, em condiçôes de casa de vegetaçẫo. Em condiçôes similares com mudas de trigo e arroz, RADWAN et al., (2004) obtiveram redução no comprimento e na área da superfície radicular pela inoculação de Azospirillum. Estes efeitos foram atribuídos à produção de indóis (auxinas) e à utilização de estirpes de Azospirillum que foram mais eficientes na produção de indol. A crotalária pode ter proporcionado ambiente favorável ao desenvolvimento das bactérias e a maior síntese de auxinas, reduzindo o perfilhamento e o NP do arroz.

As doses de N aumentaram o NP de maneira linear crescente (Figura 5). O ajuste do NP à equação linear também foi obtido por CAZETTA et al. (2008), pelo aumento das doses de $\mathrm{N}$ até a dose de $125 \mathrm{~kg} \mathrm{ha}^{-1}$. Hernandes et al. (2010), avaliando doses de $\mathrm{N}$ em coberturas do arroz até a dose de $200 \mathrm{~kg} \mathrm{ha}^{-1}$, obtiveram ajuste a uma equação quadrática sobre o NP, cuja estimativa da dose máxima de N (128 kg ha-1 de N) proporcionou o maior valor do NP (251), com ambos os autores avaliando o arroz em SPD em condiçôes iguais de solo e presença de irrigação suplementar. $\mathrm{O}$ nitrogênio aumenta o perfilhamento do arroz e garante sua sobrevivência tornando-os produtores de panículas.

Para o número de EG e EC não houve influencia dos fatores avaliados (Tabela 2). Semelhante ao presente trabalho, quanto às coberturas vegetais, CAZETTA et al. (2008) para o milheto, crotalária e guandu, e Bordin et al. (2003) para milheto e crotalária, não obtiveram diferenças para o número de EG e EC cultivando o arroz em sucessão as coberturas vegetais. A suplementação de água pela irrigação por aspersão, permitiu que os períodos de estiagem que ocorreram durante o desenvolvimento vegetativo, reprodutivo

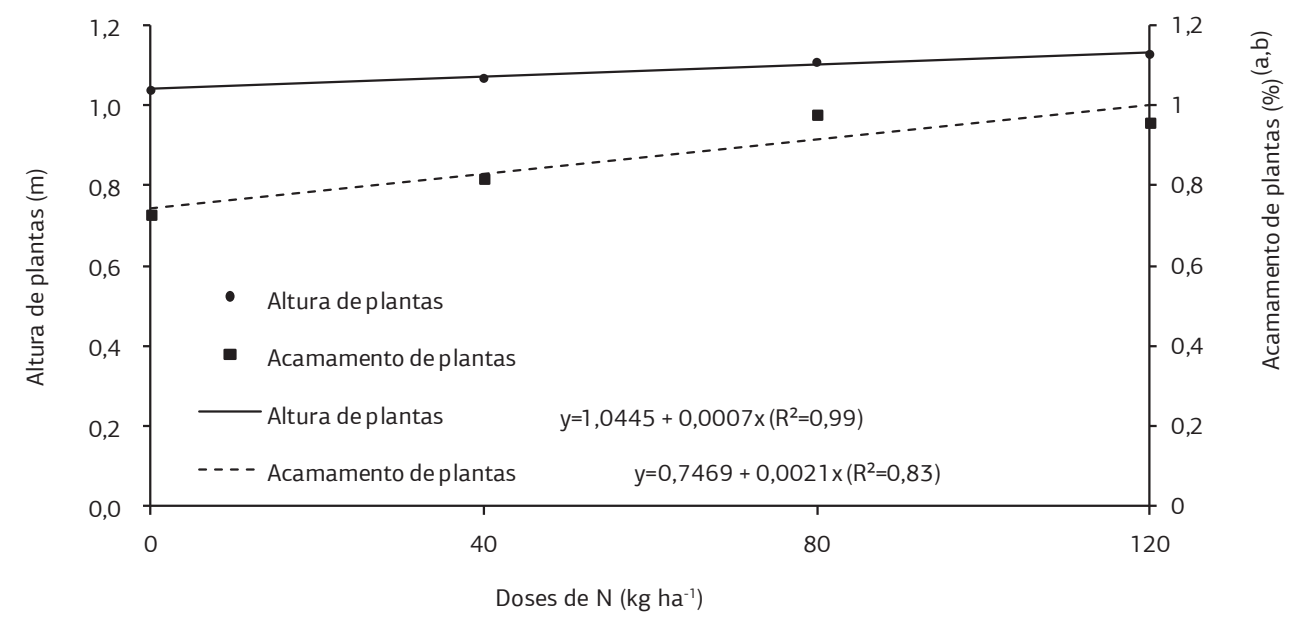

Figura 3. Altura e acamamento de plantas do arroz de terras altas no sistema plantio direto, em função das doses de $\mathrm{N}$ em cobertura. Selvíria (MS), Brasil, 2012. ( $\left.{ }^{a}\right)$ Escala de notas para acamamento: 0 (sem acamamento), 1 (até 5\% de plantas acamadas), 2 (5 a $25 \%$ ), 3 (25 a 50\%), 4 (50 a 75\%) e 5 (75 a 100\% de plantas acamadas); ( $\left.{ }^{b}\right)$ Dados transformados em $(x+0,5)^{0,5}$. 
e de maturação do arroz não interferissem no número de EG, como constatado por Crusciol et al. (2003).

$\mathrm{Na}$ massa de cem gráos foi observada a influência da interação entre as coberturas vegetais e a inoculação de sementes com A. brasilense (Figura 4a). No cultivo do arroz submetido à inoculação em sucessão ao milheto, verificou-se menor massa de cem grãos $(2,51 \mathrm{~g})$ em relação ao tratamento náo inoculado $(2,62 \mathrm{~g})$. A redução da massa de cem gráos do arroz inoculado em sucessão ao milheto pode ter ocorrido pelo menor aporte de $\mathrm{N}$ no sistema (SALA et al., 2007). A maior necessidade dos microrganismos pelo $\mathrm{N}$ para decompor a palha de maior $\mathrm{C} / \mathrm{N}$ do milheto, como também, sua velocidade lenta de decomposição/mineralização (TorRes et al., 2008) contribuíram para reduzir o aporte de N.
A produtividade do arroz foi influenciada pelas doses de $\mathrm{N}$ em cobertura e as coberturas vegetais (Tabela 2). As doses de $\mathrm{N}$ em cobertura aumentaram a produtividade do arroz de maneira quadrática (Figura 5). A estimativa da dose e produtividade foram de $107 \mathrm{~kg} \mathrm{ha}^{-1}$ de $\mathrm{N}$ e $4674 \mathrm{~kg}$ ha $^{-1}$ respectivamente. Para Hernandes et al. (2010), a estimativa da dose de $\mathrm{N}$ e da produtividade do arroz foram de $122 \mathrm{~kg} \mathrm{ha}^{-1}$ de N e $4.240 \mathrm{~kg} \mathrm{ha}^{-1}$.

A produtividade do arroz em sucessão ao guandu e a braquiária obtiveram diferença, sendo a maior (4709 $\left.\mathrm{kg} \mathrm{ha}{ }^{-1}\right)$ e a menor (3880 $\left.\mathrm{kg} \mathrm{ha}^{-1}\right)$ produtividade respectivamente (Figura 6). O ranking de produtividade em ordem decrescente obtido pelo arroz cultivado em sucessão às coberturas vegetais foi: guandu $\left(4709 \mathrm{~kg} \mathrm{ha}^{-1}\right)$

(a)

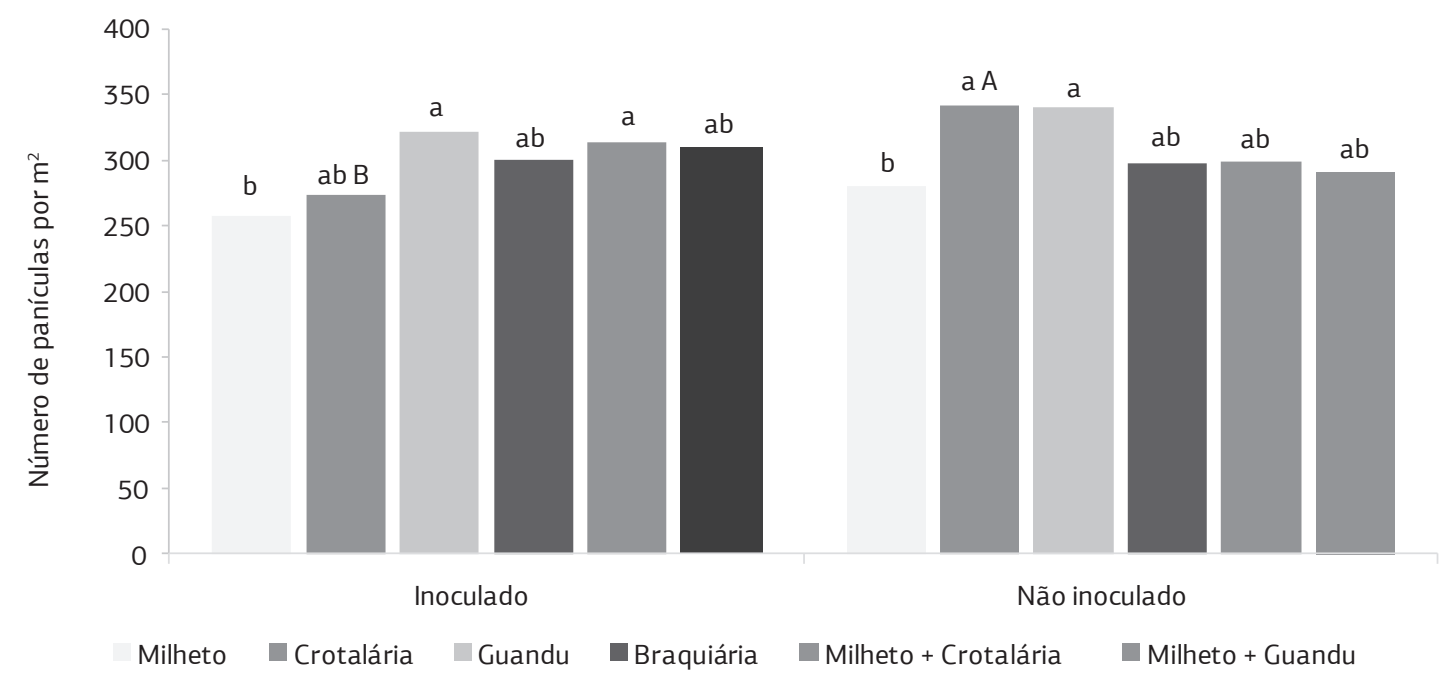

(b)

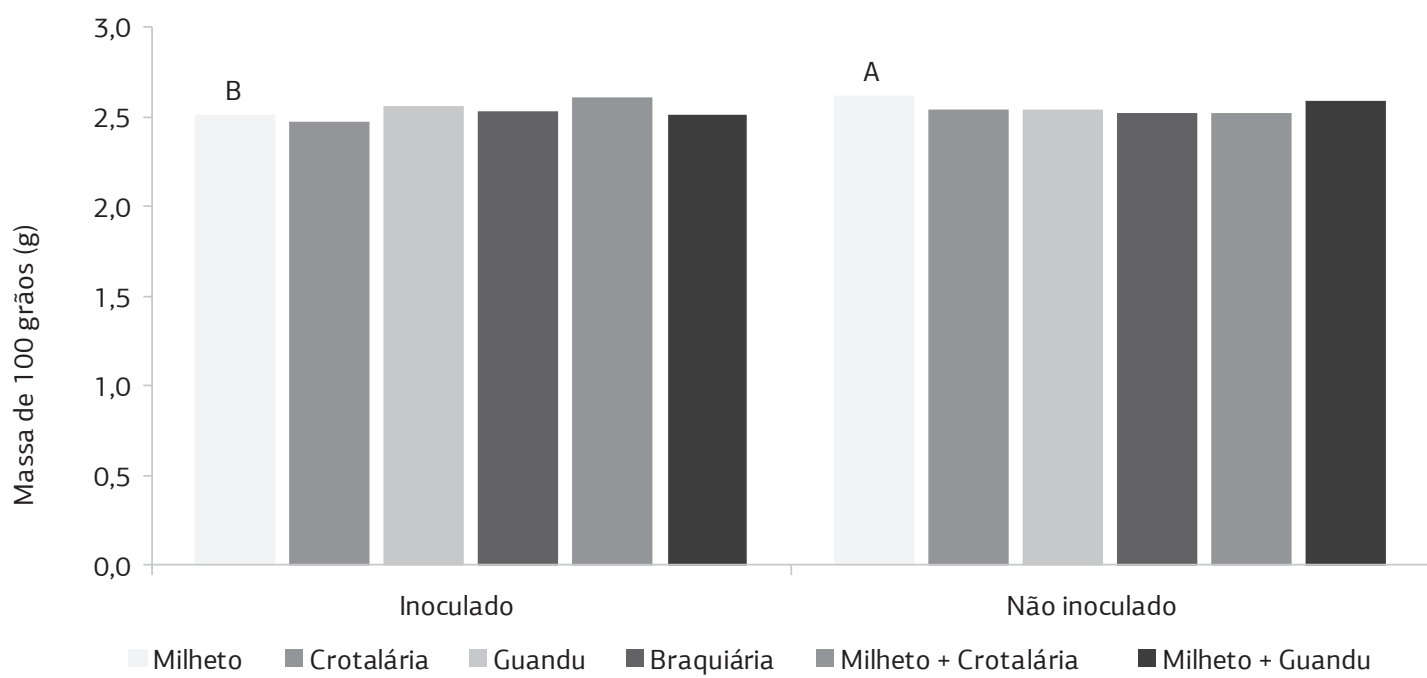

Figura 4. Desdobramento da interação entre coberturas vegetais e inoculação de sementes com $A$. brasilense sobre o número de panículas por $\mathrm{m}^{2}$ (a) e a massa de cem grãos (b). Selvíria (MS), Brasil, 2012. Número de panículas por $\mathrm{m}^{2}$ - coberturas vegetais dentro de inoculação; DMS=54,7 (letras minúsculas), inoculação dentro de coberturas vegetais; DMS=37,4 (letras maiúsculas). Massa de cem grãos - inoculação dentro de coberturas vegetais; DMS=0,10 (letras maiúsculas). Médias seguidas por letra minúsculas e maiúsculas iguais não diferem entre si pelo teste de Tukey a 5\% de probabilidade. 


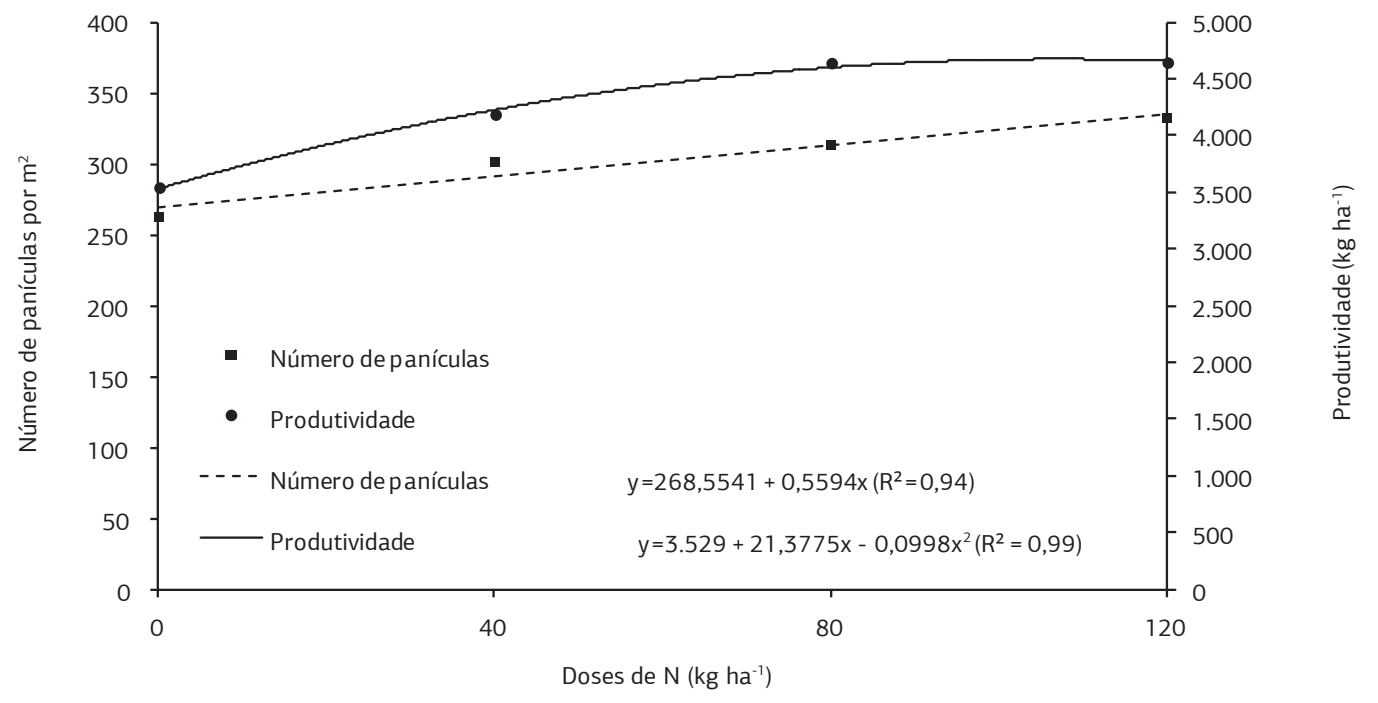

Figura 5. Número de panículas por $\mathrm{m}^{2}$ e produtividade do arroz de terras altas no sistema plantio direto em função das doses de $\mathrm{N}$ em cobertura. Selvíria (MS), Brasil, 2012.

Tabela 2. Resultados da análise de variância das variáveis: matéria seca da parte aérea do arroz (MSPA), teor de N foliar (TN), altura de plantas (AP), acamamento de plantas (AC), número de panículas por $\mathrm{m}^{2}(\mathrm{NP})$, espiguetas granadas (EG), espiguetas chochas (EC), massa de cem grãos (MG) e produtividade (PR) do arroz de terras altas no sistema plantio direto. Selvíria (MS), Brasil, 2012

\begin{tabular}{|c|c|c|c|c|c|c|c|c|c|}
\hline \multirow{2}{*}{ Teste F } & MSPA & TN & AP & $A C$ & NP & EG & EC & MG & PR \\
\hline & kg ha-1 & g kg $^{-1}$ & m & $\%$ & n. ${ }^{\circ} \mathbf{m}^{-2}$ & n. ${ }^{\circ}$ pan $^{-1}$ & $\%$ & g & kg ha $^{-1}$ \\
\hline C & $3,44^{* *}$ & $1,25^{\mathrm{ns}}$ & $1,25^{\mathrm{ns}}$ & $1,67^{\text {ns }}$ & $4,45^{* *}$ & $0,75^{\text {ns }}$ & $1,74^{\mathrm{ns}}$ & $0,72^{\text {ns }}$ & $2,61^{*}$ \\
\hline I & $0,01^{\mathrm{ns}}$ & $0,14^{\mathrm{ns}}$ & $1,33^{\mathrm{ns}}$ & $1,90^{\text {ns }}$ & $2,65^{\text {ns }}$ & $0,69^{\text {ns }}$ & $3,12^{\text {ns }}$ & $1,20^{\text {ns }}$ & $0,83^{\text {ns }}$ \\
\hline D & $25,85^{* *}$ & $17,32^{* *}$ & $27,43^{* *}$ & $5,43^{* *}$ & $14,86^{* *}$ & $1,70^{\text {ns }}$ & $0,79^{\text {ns }}$ & $2,13^{\text {ns }}$ & $10,59^{* *}$ \\
\hline$C \times I$ & $2,14^{* *}$ & $2,15^{* *}$ & $1,96^{\mathrm{ns}}$ & $2,08^{\text {ns }}$ & $2,89^{*}$ & $0,51^{\text {ns }}$ & $0,72^{\mathrm{ns}}$ & $2,30^{*}$ & $2,03^{\text {ns }}$ \\
\hline$C \times D$ & $0,95^{\mathrm{ns}}$ & $0,38^{\text {ns }}$ & $0,47^{\mathrm{ns}}$ & $0,41^{\mathrm{ns}}$ & $0,53^{\text {ns }}$ & $1,14^{\mathrm{ns}}$ & $0,88^{\text {ns }}$ & $0,54^{\text {ns }}$ & $0,36^{\mathrm{ns}}$ \\
\hline$I \times D$ & $0,66^{\mathrm{ns}}$ & $0,39^{\text {ns }}$ & $0,44^{\mathrm{ns}}$ & $0,78^{\text {ns }}$ & $0,98^{\text {ns }}$ & $0,84^{\text {ns }}$ & $1,31^{\mathrm{ns}}$ & $0,23^{\text {ns }}$ & $0,19^{\text {ns }}$ \\
\hline$C \times I \times D$ & $0,88^{\mathrm{ns}}$ & $0,73^{\mathrm{ns}}$ & $0,81^{\mathrm{ns}}$ & $0,53^{\text {ns }}$ & $1,44^{\mathrm{ns}}$ & $1,01^{\mathrm{ns}}$ & $0,93^{\text {ns }}$ & $1,28^{\text {ns }}$ & $0,51^{\mathrm{ns}}$ \\
\hline DMS(5\%) & - & - & - & - & - & - & - & - & 806 \\
\hline CV(\%) & 7,42 & 20,89 & 4,67 & 40,66 & 17,73 & 14,66 & 26,86 & 5,7 & 22,56 \\
\hline
\end{tabular}

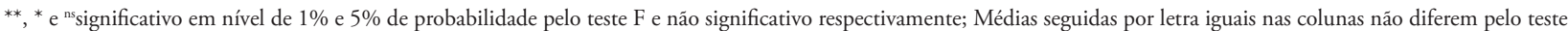
de Tukey em nível de 5\% de probabilidade; DMS: diferença mínima significativa pelo teste de Tukey; CV: coeficiente de variação.

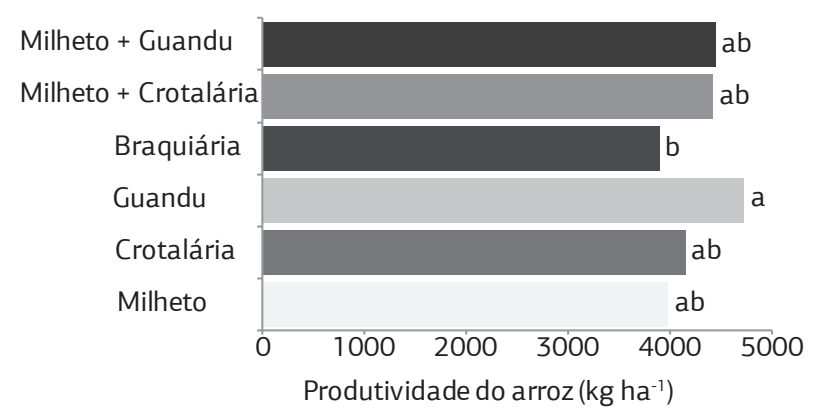

Figura 6. Produtividade do arroz de terras altas no sistema plantio direto em sucessão às coberturas vegetais. Selvíria (MS), Brasil, 2012. DMS=806. Médias seguidas por letra minúsculas iguais não diferem entre si pelo teste de Tukey a $5 \%$ de probabilidade.
$>$ milheto + guandu $\left(4432 \mathrm{~kg} \mathrm{ha}^{-1}\right)>$ milheto + crotalária $\left(4400 \mathrm{~kg} \mathrm{ha}^{-1}\right)>$ crotalária $\left(4137 \mathrm{~kg} \mathrm{ha}^{-1}\right)>$ milheto $(3961$ $\left.\mathrm{kg} \mathrm{ha}^{-1}\right)>$ braquiária $\left(3880 \mathrm{~kg} \mathrm{ha}^{-1}\right)$. As primeiras posiçóes foram obtidas pelas coberturas vegetais que tinham palha de espécies leguminosas, com destaque para o guandu que, tanto em cultivo exclusivo como em consórcio proporcionou as maiores produtividades ao arroz. A crotalária ocupou posiçóes intermediárias de produtividade entre as seis coberturas vegetais e nas duas últimas posiçóes, o milheto e a braquiária, com produtividades abaixo dos $4000 \mathrm{~kg} \mathrm{ha}^{-1}$.

O histórico dos sistemas de produção utilizados na área experimental mantido há três anos (2009/2010, 2010/2011 e 2011/2012), com as coberturas vegetais cultivadas anteriormente ao arroz na primavera, arroz no verão e trigo no inverno, provavelmente contribui para o maior aporte de $\mathrm{N}$ no solo com leguminosas (Perin et al., 
2004; Teodoro et al., 2011) e aos atributos físicos do solo, pelos poros deixados pelas raízes do guandu e crotalária (ANDRADE et al., 2009). Desta forma, podendo aumentar o volume de solo explorado pelas raízes do arroz.

A inoculação de sementes com $A$. brasilense não influenciou a produtividade do arroz. Entre os componentes de produção avaliados, a inoculação de sementes aumentou a massa de cem grãos do arroz em sucessão ao milheto + guandu, porém não refletiu em aumento de produtividade.

\section{CONCLUSÃO}

Os cultivos antecessores influenciaram a produtividade do arroz, sendo a maior produção alcançada após o cultivo de guandu e a menor após o cultivo de braquiária. A dose de 107 $\mathrm{kg} \mathrm{ha}^{-1} \mathrm{de} \mathrm{N}$ em cobertura, na forma de ureia, proporcionou a maior produtividade do arroz em SPD, independentemente da cultura de cobertura antecessora. A inoculação das sementes $\operatorname{com} A$. brasilense não influenciou a produtividade do arroz.

\section{AGRADECIMENTOS}

À Fundação AGRISUS pela concessão de bolsa de mestrado ao primeiro autor, e aos funcionários da Fazenda de Ensino, Pesquisa e Extensão da Faculdade de Engenharia de Ilha Solteira - UNESP.

\section{REFERÊNCIAS}

ANDRADE, R.S.; STONE, L.F; SILVEIRA, P.M. Culturas de cobertura e qualidade física de um Latossolo em plantio direto. Revista Brasileira de Engenharia Agrícola e Ambiental, v.13, p.411-418, 2009.

BALDANI, J.I.; BALDANI, V.L.D. History on the biological nitrogen fixation research in graminaceous plants: special emphasis on the Brazilian experience. Anais da Academia Brasileira de Ciências, v.77, p. 549-579, 2005.

BORDIN, L.; FARINELLI, R.; PENARIOL, F.G.; FORNASIERI FILHO, D. Sucessão de cultivo de feijāo-arroz com doses de adubação nitrogenada após adubação verde, em semeadura direta. Bragantia, v.62, p.417-428, 2003.

CRUSCIOL, C.A.A.; ARF, O.; SORATTO, R.P.; MACHADO, J.R. Influência de lâminas de água e adubação mineral na nutriçáo e produtividade de arroz de terras altas. Revista Brasileira de Ciência do Solo, v.27, p.647-654, 2003.

CAZETTA, D.A.; ARF, O.; BUZETTI, S.; SÁ, M.E.; RODRIGUES, R.A.F. Desempenho do arroz de terras altas com a aplicaçáo de doses de nitrogênio e em sucessão às culturas de cobertura do solo em sistema de plantio direto. Bragantia, v.67, p.471-479, 2008.

DÖBEREINER, J.; MARRIEL, I.; NERY, M. Ecological distribution of Spirillum lipoferum Beijerinck. Canadian Journal of Microbiology, v.22, p.1464-1473, 1976.
EMPRESA BRASILEIRA DE PESQUISA AGROPECUÁRIA (EMBRAPA). Sistema Brasileiro de Classificação de Solos. 2.ed. Rio de Janeiro: EMBRAPA/CNPSo, 2006. 306p.

GUIMARÃES, S.L.; BALDANI, J.I.; BALDANI, V.L.D. JACOBNETO, J. Adição de molibdênio ao inoculante turfoso com bactérias diazotróficas usado em duas cultivares de arroz irrigado. Pesquisa Agropecuária Brasileira, v.42, p.393-398, 2007.

HERNANDES, A.; BUZETTI, S.; ANDREOTTI, M.; ARF, O.; SÁ, M.E. Doses, fontes e épocas de aplicação de nitrogênio em cultivares de arroz. Ciência e Agrotecnologia, v.34, p.307-312, 2010.

KUSS, A.V.; KUSS, V.V.; LOVATO, T.; FLÔRES, M. L. Fixação de nitrogênio e produção de ácido indolacético in vitro por bactérias diazotróficas endofíticas. Pesquisa Agropecuária Brasileira, v.42, p.1459-1465, 2007.

MALAVOLTA, E.; VITTI, G.C.; OLIVEIRA, S.A. Avaliação do Estado Nutricional das Plantas: princípios e aplicações. Piracicaba: Potafós, 1997. 319p.

NASCIMENTO, V.; ARF, O.; SILVA, M.G.; BINOTTI, F.F.S.; RODRIGUES, R.A.F; ALVAREZ, R.C.F. Uso do regulador de crescimento etil-trinexapac em arroz de terras altas. Bragantia, v.68, p.921-929, 2009.

PERIN, A.; SANTOS, R.H.S.; URQUIAGA, S.; GUERRA, J.G.M.; CECON, P.R. Produção de fitomassa, acúmulo de nutrientes e fixação biológica de nitrogênio por adubos verdes em cultivo isolado e consorciado. Pesquisa Agropecuária Brasileira, v.39, p.35-40, 2004.

RADWAN, T.E.E.; MOHAMED, Z.K.; REIS, V.M. Efeito da inoculação de Azospirillum e Herbaspirillum na produção de compostos indólicos em plântulas de milho e arroz. Pesquisa Agropecuária Brasileira, v.39, p.987-994, 2004.

RODRIGUES, E.P.; RODRIGUES, L.S.; OLIVEIRA, A.L.M.; BALDANI, V.L.D.; URQUIAGA, S.; REIS, V.M. Azospirillum amazonense inoculation: effects on growth, yield and N2 fixation of rice (Oryza sativa L.). Plant and Soil, v.302, p.249-261, 2008.

SALA, V.M.R.; CARDOSO, E.J.B.N.; FREITAS, J.G.; SILVEIRA, A.P.D. Resposta de genótipos de trigo à inoculaçáo de bactérias diazotróficas em condiçóes de campo. Pesquisa Agropecuária Brasileira, v.42, p.833-842, 2007.

TEIXEIRA, C.M.; CARVALHO, G.J.; ANDRADE, M.J.B.; SILVA, C.A.; PEREIRA, J.M. Decomposição e liberação de nutrientes das palhadas de milheto e milheto + crotalária no plantio direto do feijoeiro. Acta Scientiarum: Agronomy, v.31, p.647-653, 2009.

TEODORO, R.B.; OLIVEIRA, F.L.; SILVA, D.M.N.; FÁVERO, C.; QUARESMA, M.A.L. Aspectos agronômicos de leguminosas para adubação verde no cerrado do alto vale do Jequitinhonha. Revista Brasileira de Ciência do Solo, v.35, p.635-643, 2011.

TORRES, J.L.R.; PEREIRA, M.G.; FABIAN, A.J. Produção de fitomassa por plantas de cobertura e mineralização de seus resíduos em plantio direto. Pesquisa Agropecuária Brasileira, v.43, p.421-428, 2008. 